\title{
Development and characterization of an FK photovoltaic concentrator for maximum conversion efficiency
}

\author{
Pablo Zamora a , Maikel Hernández ${ }^{\text {b }}$, Juan Vilaplana ${ }^{\text {b }}$, Pablo Benítez ${ }^{\text {a,b }}$, Rubén Mohedano b , Juan \\ C. Miñano ${ }^{a, b}$ \\ ${ }^{\text {a }}$ Technical University of Madrid (UPM), Campus de Montegancedo 28223 Madrid, Spain \\ ${ }^{\mathrm{b}}$ LPI-LLC, 2400 Lincoln Ave., Altadena, CA 91001, USA
}

\begin{abstract}
The outdoor measurements of a single-cell concentrator PV module reaching a regressed 35.6\% efficiency and a maximum peak efficiency of $36.0 \%$ (both corrected @ $T_{\text {cell }}=25^{\circ} \mathrm{C}$ ) are presented. This is the result of the joint effort by LPI and Solar Junction to demonstrate the potential of combining their respective state-of-the-art concentrator optics and solar cells. The LPI concentrator used is an FK, which is an advanced nonimaging concentrator using 4-channel Köhler homogenization, with a primary Fresnel lens and a refractive secondary made of glass. Solar Junction's cell is a triplejunction solar cell with the A-SLAM ${ }^{\mathrm{TM}}$ architecture using dilute-nitrides.
\end{abstract}

Keywords: Fresnel lens, nonimaging, concentrator, photovoltaic, solar energy, Köhler integration

\section{INTRODUCTION}

High concentration photovoltaics (HCPV) is a promising option to further reduce the solar electricity costs thanks to the continuous increases in efficiency of the triple junction cell technology at very high concentration levels. The present world record in the HCPV concentration range is $44.0 \%$ (recently surpassed by Japanese manufacturer Sharp with $44.4 \%$, but for much lower concentration levels, 302x [1]), achieved by a Solar Junction's cell with its A-SLAM ${ }^{\mathrm{TM}}$ lattice matched architecture and operating at 947x concentration [2]. This efficiency nearly doubles that of the best commercial 1-sun silicon solar cells, and there is a clear path for further efficiency improvements by increasing the number of junctions.

However, to take full advantage of this high efficiency, these cells must be combined with concentrator optics that provide the required high concentration with a high optical efficiency and sufficient tolerances (reflected in the concentrator acceptance angle) to keep the cost low and the efficiency high at the real world array level. Additionally, the concentrator must also provide good spatial homogeneity of the cell illumination for the three junctions, which is an aspect that has been underestimated until recently [3].

In the last few years a new photovoltaic concentrator, called the FK, has been proposed by LPI to provide the state-ofthe-art optical performance [4]. It is comprised of a four-fold symmetrical Fresnel lens and a four-fold secondary lens attached to the cell which, acting together, produce Köhler homogenization through its four separate channels. This device is able to provide simultaneously high optical efficiency, high concentration, excellent spatial and spectral uniformity and high acceptance angle. The high performance of the FK has been demonstrated by means of experimental measurements [5].

During the past few months, LPI and Solar Junction have been collaborating to design and manufacture a proof of concept prototype to demonstrate that very high module efficiencies can be obtained by combining Solar Junction's cells with LPI's optics, and that this can be achieved with both, very high concentration and high acceptance angle, features of crucial interest in the cost effectiveness of CPV systems. The first results of the complete prototype will be detailed along the text. 


\section{CONCENTRATOR MODULE DESIGN PROCEDURE}

A CPV module contains two main elements, the solar cell and the optical concentrator, which cannot be designed independently from the cell chosen for the module. In order to obtain the best module performance, it is vital that the optical design of the concentrator takes into account the particular features of the chosen solar cell, so the latter is able to optimally perform with the illumination provided by the optical concentrator.

To obtain high module efficiencies, the optical concentrator must fulfill several issues. First, high optical efficiency must be achieved by maximizing the luminous power delivered to the cell, which implies a minimization of the optical losses (absorption, Fresnel losses,...) by choosing high-transmission materials. Secondly, the concentrator should present a proper distribution of the spectral transmission along the whole cell spectral range. This spectral transmission takes into account the External Quantum Efficiencies (EQEs) of the different junctions of the cell, so the combination of both ensures a balance of the generated photocurrent by the different junctions and consequently a maximization of the photocurrent provided by the whole device (i.e. current matching) for a particular spectral distribution. Finally, as stated in the introduction, the concentrator must also provide good spatial homogeneity of the cell illumination for the three junctions. This contributes, not only to the aforementioned balance of photocurrents, but also significantly to the total power delivered by the cell, which strongly depends on the fill-factor (FF) of the I-V curve. The FF is negatively affected by non-uniform profiles since they increase the cell series resistance effects, as has been widely discussed in previous publications [3][6].
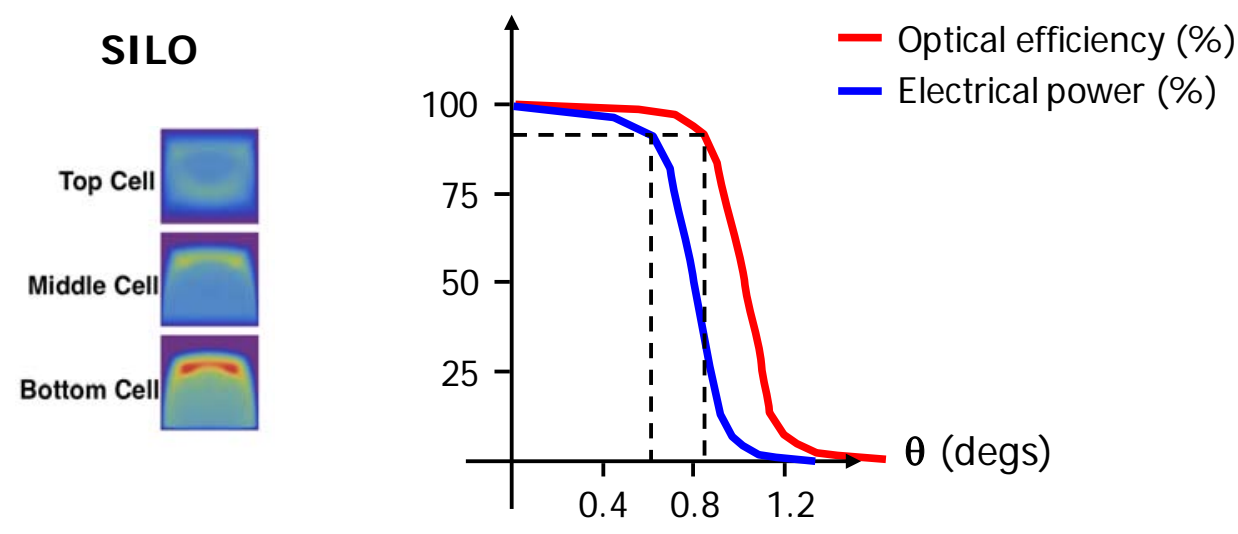

\section{FK concentrator}
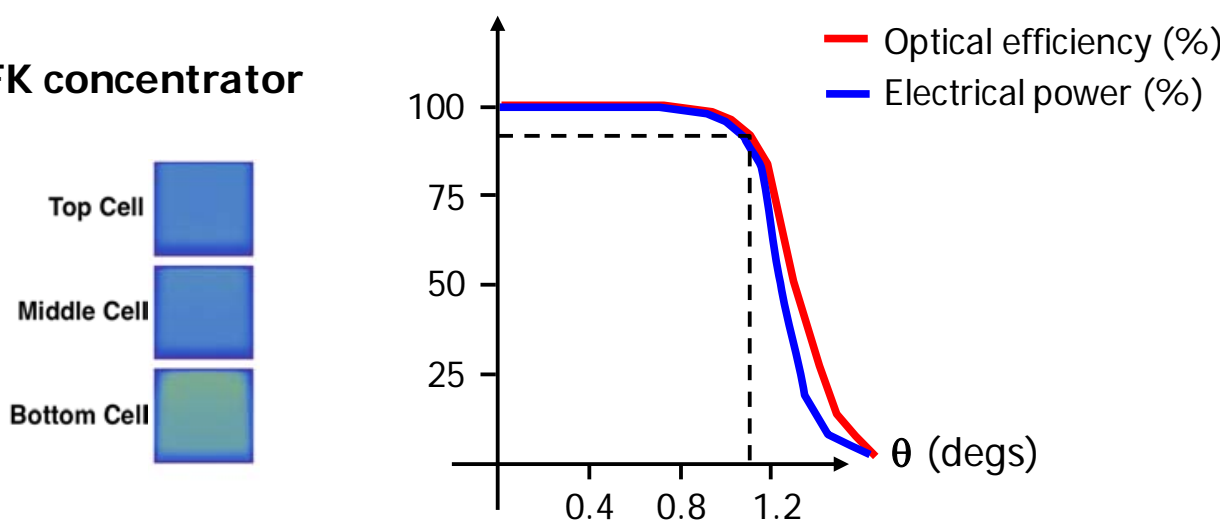

Figure 1 Irradiance non-homogeneities and chromatic dispersion negative effects on a CPV module performance. Left: irradiance profiles for the three sub-cells (top, middle, bottom) when the module is misaligned $0.6^{\circ}$, for a Fresnel-based 
concentrator as the SILO (top) and for the FK concentrator (bottom). Right: optical efficiency (in red) and electrical power (in blue) curves showing their dependences with the module misalignment.

This last issue can be graphically explained through Figure 1, which shows simulated irradiance profiles (taken from [3]) for two different optical concentrators performing at $0.6^{\circ}$ off-axis position. The irradiance profiles of the different subcells (top, middle and bottom) are shown for a SILO [7] and for an FK concentrator, both of them presenting identical optical parameters $\left(C_{g}, f\right.$-number, materials). Note that, instead of the SILO, any other classical Fresnel-based concentrator could have been chosen (RTP, XTP) with similar results. The influence of chromatic dispersion of irradiance on the different junctions is evident in a classic Fresnel-based concentrator, since the electrical power is much more sensitive to the sun's incidence angle than the optical efficiency itself. In the FK concentrator the effect is hardly noticeable because of the well-balanced irradiance uniformity, no matter the wavelength or incidence angle of sunlight. The curves plotted show that, while the SILO is delivering around $90 \%$ of the nominal electrical power at a $0.6^{\circ}$ off-axis situation, the FK concentrator is well above a $99 \%$ value.

As a consequence of what has been exposed in this section, in order to match the LPI concentrator to the SJ solar cell, a long and careful process of choosing the design parameters has been carried out since a vast range of parameters are suitable for the FK concentrator. Among them, the most challenging ones are the geometrical concentration $\left(C_{g}\right)$, the compactness (defined by the $f$-number) and the optical element materials. An exhaustive analysis of the cell performance under the illumination produced by the LPI concentrator has been carried out on the different alternatives initially proposed. This analysis has included detailed ray tracing simulations of the concentrator carried out by LPI to obtain the transmission function $\mathrm{T}(\mathrm{x}, \mathrm{y}, \lambda)$, where $\lambda$ is the wavelength of the light (for values within the SJ solar cell spectral range of interest) and $\mathrm{x}-\mathrm{y}$ are the coordinates that define the position on the solar cell surface. This information has served as the input for SJ to model the cell under an arbitrary sun spectrum (but with special interest in the AM1.5d), using a discretized circuit model with lumped components which can be analyzed with a standard circuit analysis software for non-linear electric circuits (such as PSPICE). Modeled efficiencies surpassing 36\% for the module were predicted, which encouraged the team to prove it out in real prototypes.

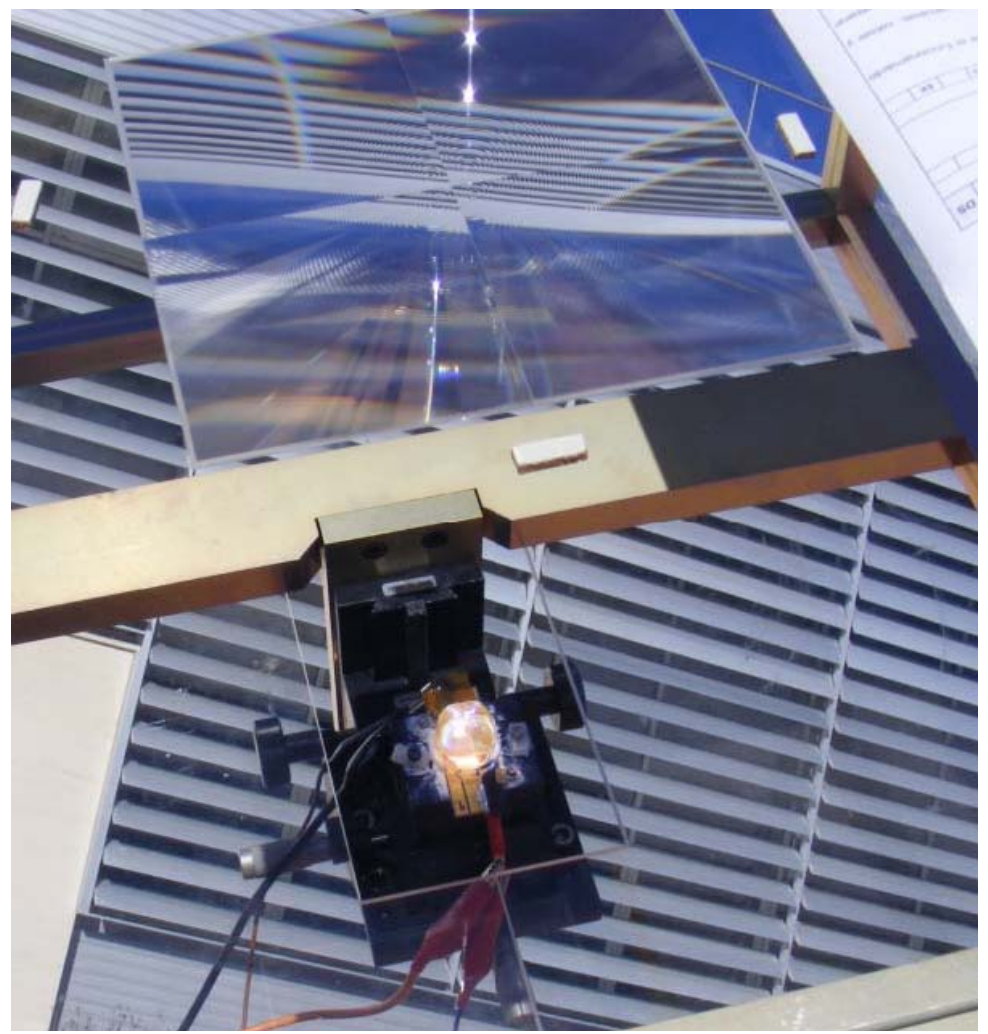

Figure 2 FK concentrator prototype employed for the measurements. At top, the 4-fold Fresnel lens POE; at bottom, the receiver, including the solar cell (Solar Junction's A-SLAM ${ }^{\mathrm{TM}}$ ) and the SOE. 


\section{EXPERIMENTAL RESULTS}

The prototype of the FK concentrator manufactured for the measurements shown in this work presents a geometrical concentration of $\mathrm{Cg}=1,024 \mathrm{x}$, taking into account the lens active area and the cell illuminated area. The FK concentrator achieves an acceptance angle of $\alpha=0$ bt that concentration level. The experimental results shown in this section correspond to outdoor measurements carried out on the first complete single-cell module (see Figure 2).

The measurements were done with a I-V curve tracer with a capacitive load at the Cedint facilities of the Technical University of Madrid (outside of Madrid city, at latitude: 40,4045, longitude: -3,8349) by LPI personnel. There are two different sets of measurements: the first of them took 1.5 hours on April $18^{\text {th }} 2013$, while the second was carried out on August $20^{\text {th }} 2013$ during 2 hours.

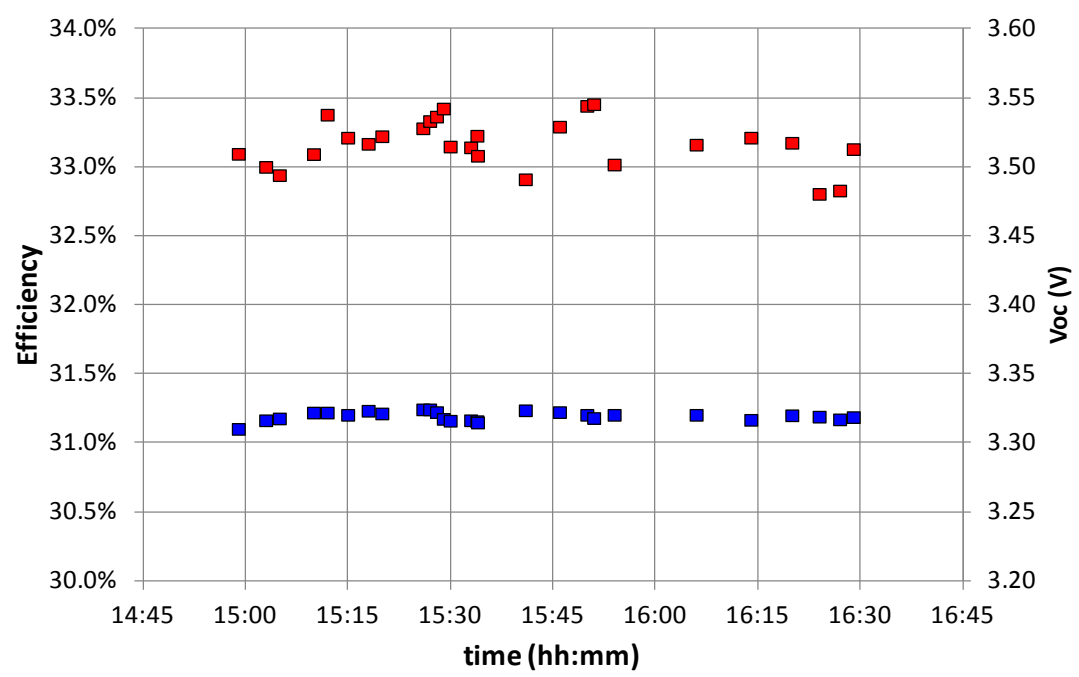

Figure 3 Efficiencies (in blue) and open circuit voltages (in red) as measured, without temperature or irradiance correction, for the April measurements. DNI $=961 \pm 1.5 \% \mathrm{~W} / \mathrm{m} 2$ during the tests.

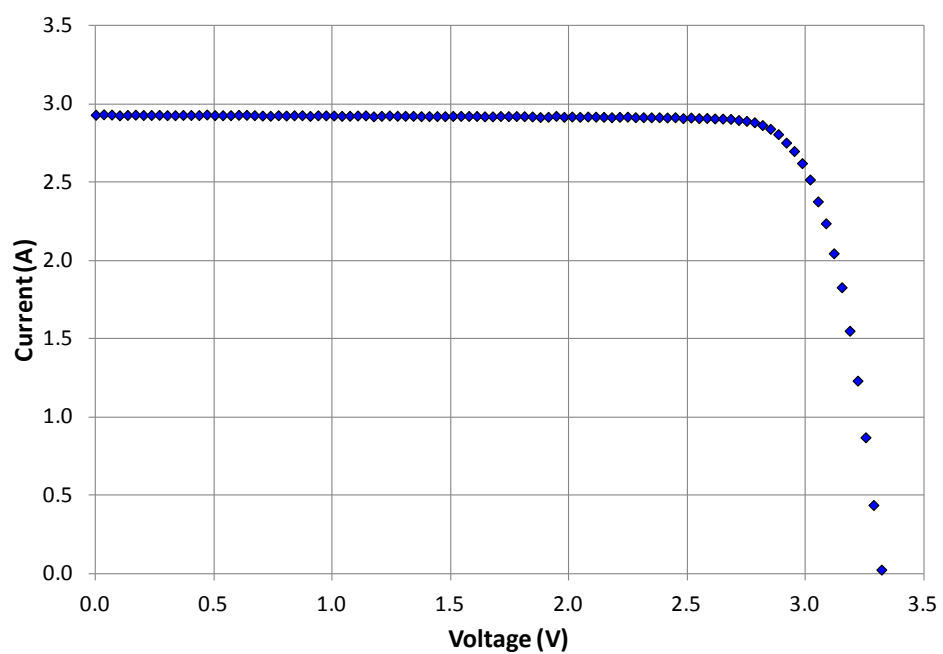

Figure 4 Measured I-V curve on April 18 ${ }^{\text {th }}$, 2013 at 15:51. DNI $=946 \mathrm{~W} / \mathrm{m} 2 ;$ Voc $=3.32 \mathrm{~V}$; Isc $=2.97 \mathrm{~A} ; \mathrm{Pm}=8.22 \mathrm{~W}$, $\mathrm{FF}=0.833$; Efficiency $=33.9 \%$. 


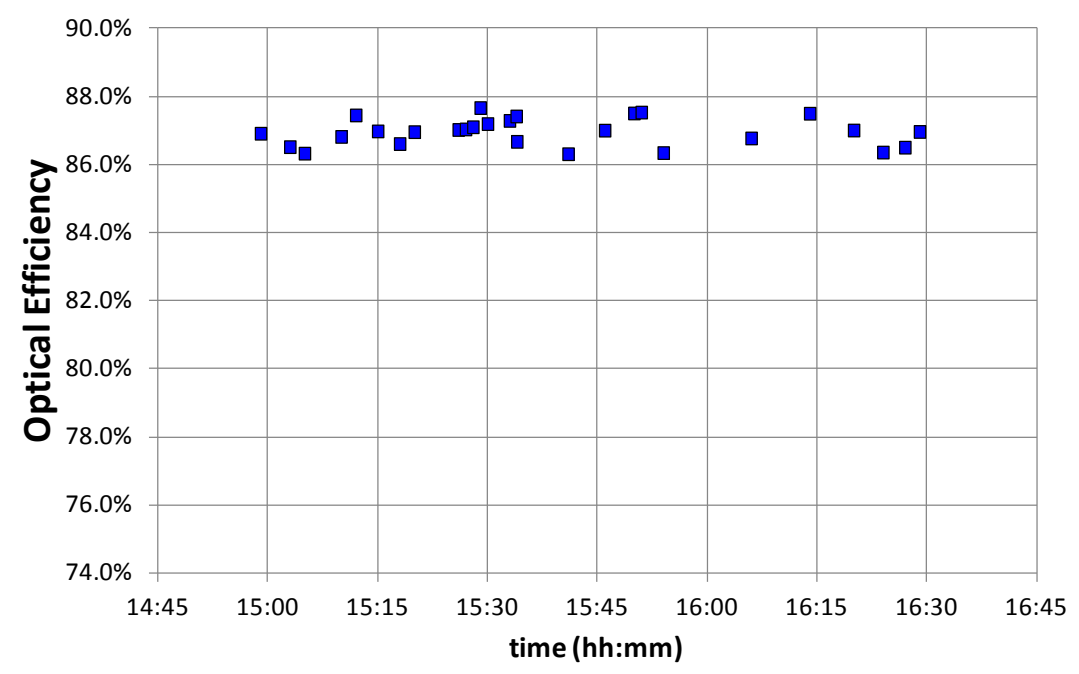

Figure 5 Optical efficiency $\left(\eta_{\text {opt }}\right)$ achieved by April measurements.

Figure 3 shows the measured efficiencies for the first set of measurements (April), ranging between 33.3-34.0\%, and the open circuit voltage values $\left(V_{o c}\right)$, that were very stable at $3.32 \mathrm{~V}$. Figure 4 shows the I-V curve of the highest instantaneous efficiency measured. In order to quantify these results with standard criteria and to establish a fair comparison among efficiency measured data from different concentrators, we have developed a model to obtain the corresponding temperature corrected efficiency values.

The optical efficiency of the concentrator has been calculated from the results obtained in Figure 3. The computed results for the whole set of measurements are shown in Figure 5, where an average value of $\eta_{\text {opt }}=87.0 \%$ can be observed.

Finally, we are interested in calculating the efficiency if the cell were at $T_{\text {cell }}=25^{\circ} \mathrm{C}$, since this value is a reference independent of both, the particular ambient conditions during measurements and the thermal design of the module. The result is shown in Figure 6, which also includes a regression curve indicating that the efficiency values measured were in the $35.3-35.5 \%$ range, with instantaneous efficiencies up to $35.7 \%$.

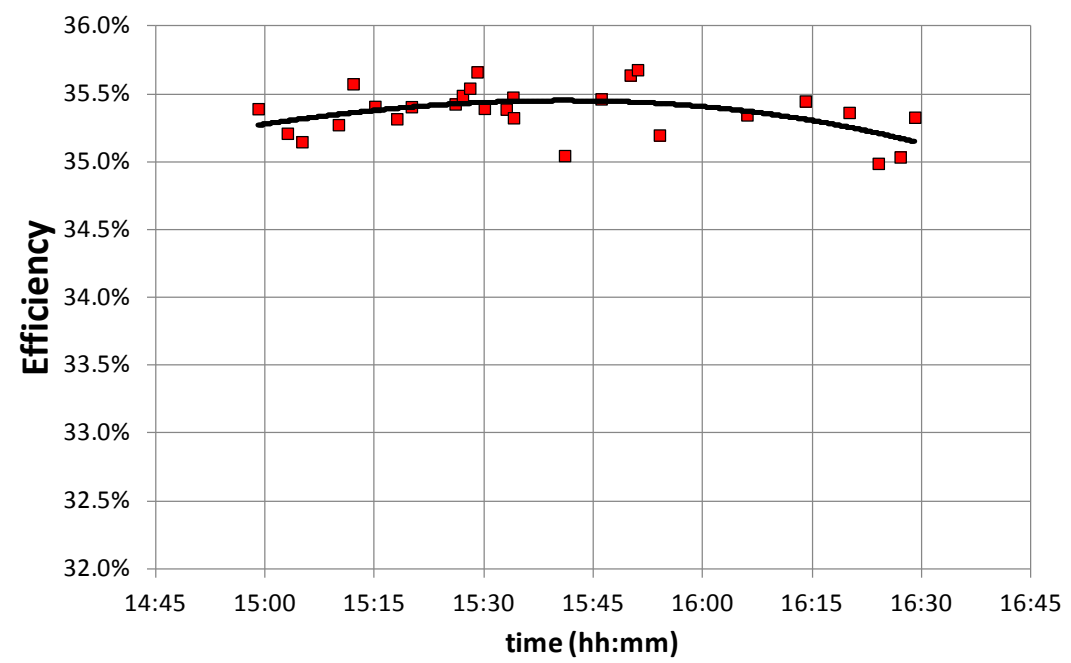

Figure 6 Measured module efficiencies in April, corrected for $T_{\text {cell }}=25^{\circ} \mathrm{C}$ 
The second set of measurements, carried out during the month of August, shows very similar results to those presented above and obtained in April. Nevertheless, measured efficiency values in August are slightly higher than those of April. Since Figures 3-6 are almost identical for the August measurements case, we will only show their temperature corrected efficiency values (see Figure 7) in order to show the efficiency increased obtained with respect to the measurements in April. As can be observed in the figure, efficiency values are in the 35.4-35.9\% range with instantaneous efficiencies up to $36.0 \%$.

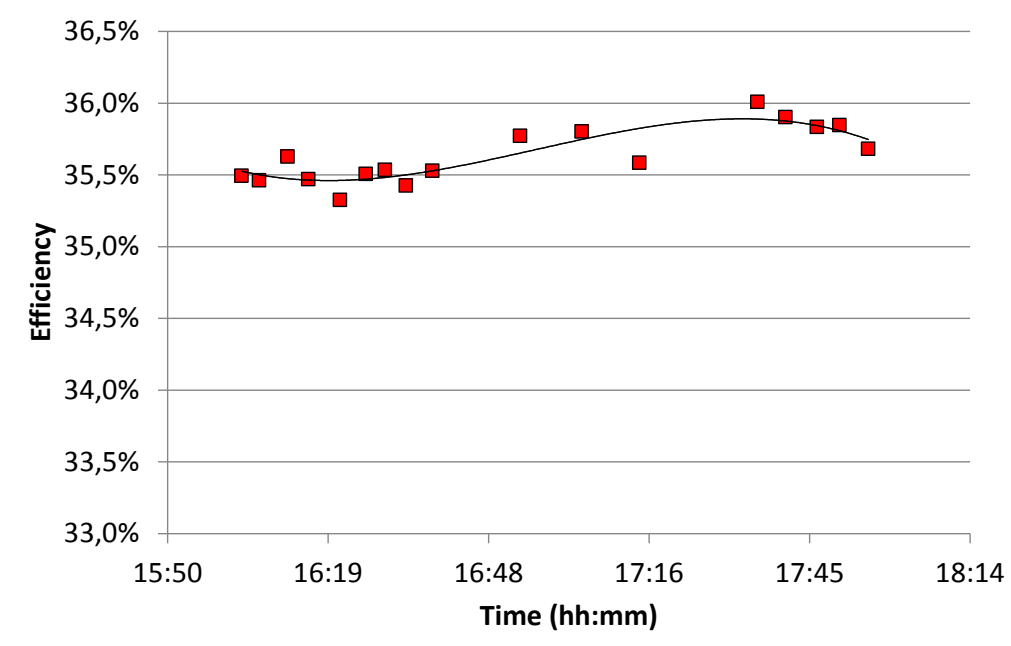

Figure 7 Measured module efficiencies in August, corrected for $T_{\text {cell }}=25^{\circ} \mathrm{C}$

\section{DISCUSSION OF THE RESULTS SIGNIFICANCE}

Achieving high efficiency CPV modules and systems relies not only on the use of high efficiency cells, but also on top performing optics. CPV modules below $30 \%$ efficiency (at $T_{\text {cell }}=25^{\circ} \mathrm{C}$ ) are the norm, and therefore showing results well over $35 \%$ efficiency is of great relevance, especially when it has been obtained with practical devices, as the FK concentrator. The results shown in this work improve the $34.5 \%$ instantaneous corrected efficiency value (to be compared with the maximum 36.0\% value obtained in Figure 7) we measured on February $14^{\text {th }} 2013$ and recently reported at CPV- 9 in Miyazaki [8], which was achieved with a still incomplete prototype.

At present, the NREL published the efficiency record on a CPV module is 35.9\% by Amonix [9]. This value has been obtained under the recently adopted CPV IEC CSTC test conditions $\left(1000 \mathrm{~W} / \mathrm{m}^{2}\right.$ direct irradiance, $\left.T_{\text {cell }}=25^{\circ} \mathrm{C}\right)$. Therefore this value is related to our corrected 35.3-35.9\% efficiencies from Figure 6 and Figure 7, meaning that we are in the same range of values than the Amonix record.

The next phase of this joint LPI-Solar Junction project will be to demonstrate these high efficiency levels with a larger primary aperture area and four cells interconnected. The FK concentrator prevents from efficiency drops when going from single-cell module level to array level, due to its large acceptance angle and its pillbox-shaped angular transmission curve (see Figure 1), which makes the FK a highly tolerant concentrator.

\section{ACKNOWLEDGEMENTS}

Authors thank the European Commission (SMETHODS: FP7-ICT-2009-7 Grant Agreement No. 288526, NGCPV: FP7ENERGY.2011.1.1 Grant Agreement No. 283798), the Spanish Ministries (ENGINEERING METAMATERIALS: CSD2008-00066, DEFFIO: TEC2008-03773, ECOLUX: TSI-020100-2010-1131, SEM: TSI-020302-2010-65 SUPERRESOLUCION: TEC2011-24019, SIGMAMODULOS: IPT-2011-1441-920000, PMEL: IPT-2011-1212920000), and UPM (Q090935C59) for the support given to the research activity of the UPM-Optics Engineering Group, making the present work possible. 


\section{REFERENCES}

[1] M.A. Green, K. Emery, Y. Hishikawa, W. Warta, E. D. Dunlop, "Solar cell efficiency tables (v42)", Prog. Photovolt: Res. Appl. 2013; 21:827-837.

[2] M.A. Green, K. Emery, Y. Hishikawa, W. Warta, E. D. Dunlop, "Solar cell efficiency tables (v41)", Prog. Photovolt: Res. Appl. 2013; 21:1-11.

[3] P. Espinet C. Algora, I. García, I. Rey-Stolle, P. Benítez, J. Chaves, A. Cvetkovic, M. Hernández, J. C. Miñano, R. Mohedano, and P. Zamora, "Triple-junction solar cell performance under Fresnel-Based concentrators taking into account chromatic aberration and off-axis operation" in $8^{\text {th }}$ International Conference on Concentrating Photovoltaic Systems, Toledo, Spain (2012).

[4] P. Benítez, J.C. Miñano, P. Zamora, R. Mohedano, A. Cvetkovic, M. Buljan, M. Hernández "High performance Fresnel-based photovoltaic concentrator”, Optics Express, 18, A25-A40, (2010).

[5] P. Zamora, P. Benítez, R. Mohedano, A. Cvetkovic, J. Vilaplana, Y. Li, M. Hernández, J. Chaves, J.C. Miñano, “Experimental characterization of Fresnel-Köhler concentrators,” J. Photon. Energy. 2(1), 021806 (2012).

[6] P. Zamora, P. Espinet-González, P. Benitez, I. García, I. Rey-Stolle, J.C. Miñano, C. Algora, "Experimental confirmation of FK concentrator insensitivity to chromatic aberrations", in $9^{\text {th }}$ International Conference on Concentrating Photovoltaic Systems, Miyazaki, Japan (2013).

[7] L.W. James, "Use of imaging refractive secondaries in photovoltaic concentrators", Contractor Report SAND897029, (1989).

[8] R. Mohedano, P. Zamora, J. Vilaplana, J. Mendes-Lopes, P. Benitez, A. Cvetkovic, M. Hernandez, J.C. Miñano, J. Chaves, G. Biot, "Ventana ${ }^{\mathrm{TM}}$ power train features and preformance", in $9^{\text {th }}$ International Conference on Concentrating Photovoltaic Systems, Miyazaki, Japan (2013).

[9] http://amonix.com/es/node/1239 